\title{
Place of Autologous Intraoperative Blood Transfusion in the Treatment of Broken Ectopic Pregnancy (EP) at the Chiphra Hospital of Ouagadougou, Burkina Faso
}

\author{
Ouattara Adama1*, Sib Sansan Rodrigue², Tougma Aline Pegwendé1, Ouédraogo Issa², \\ Zalha Assoumana ${ }^{3}$, Millogo Traoré Francoise Danielle ${ }^{1}$, Ouédraogo Charlemagne Marie ${ }^{1}$, \\ Ouédraogo Ali1, Thieba Bonané Blandine ${ }^{1}$
}

\footnotetext{
${ }^{1}$ Gynecologist Obstetrician at the University Teaching Hospital of Ouagadougou, Ouagadougou, Burkina Faso ${ }^{2}$ Gynecologist Obstetrician at the University Teaching Hospital of Ouahigouya, Ouahigouya, Burkina Faso ${ }^{3}$ Gynecologist Obstetrician at the Schiphra Hospital of Ouagadougou, Ouagadougou, Burkina Faso Email: *ouattzangaadama@yahoo.fr
}

How to cite this paper: Adama, O., Rodrigue, S.S., Pegwendé, T.A., Issa, O., Assoumana, Z., Danielle, M.T.F., Marie, O.C., Ali, O. and Blandine, T.B. (2017) Place of Autologous Intraoperative Blood Transfusion in the Treatment of Broken Ectopic Pregnancy (EP) at the Chiphra Hospital of Ouagadougou, Burkina Faso. Open Journal of Obstetrics and Gynecology, 7, 1035-1043. https://doi.org/10.4236/ojog.2017.710104

Received: August 20, 2017

Accepted: October 7, 2017

Published: October 10, 2017

Copyright $\odot 2017$ by authors and Scientific Research Publishing Inc. This work is licensed under the Creative Commons Attribution International License (CC BY 4.0).

http://creativecommons.org/licenses/by/4.0/ c) (i) Open Access

\begin{abstract}
Objective: To describe the role of autologous regenerative intraoperative bleeding of recent intra-cavity losses over the ectopic pregnancy ruptured at the Schiphra Hospital of Ouagadougou. Methodology: It has been a cross-sectional descriptive study over a period of 18 months from January $1^{\text {st }}$ 2014 to June $30^{\text {th }} 2015$ in the obstetrics and gynecology department at the schiphra hospital of Ouagadougou. In our study, we included all pregnant women having received emergency with a diagnosis of broken ectopic pregnancy complicated by a significant array of clinical haemoperitoneum and who have consented to participate in the survey. Results: During the study period, we recorded 322 cases of ectopic pregnancy, among which 106 were broken. Autotransfusion was performed in 59 patients, that is to say $18.3 \%$. The average age of patients was 27 years $(18-40)$. The average rate of childbirth was $5.25(0-11)$. The general condition of the patients was pretty good at $8.5 \%$ and poor in $91.5 \%$ of cases. The average amount of blood transfused per patient was $935 \mathrm{ml}$ with a range of 400 and $1600 \mathrm{ml}$. After autotransfusion, $62 \%$ of patients had greater improvement in hemoglobin $10 \mathrm{~g} / \mathrm{dl}$. Maternal prognosis was marked by a case of fever with a morbidity rate of $1.9 \%$ and a death post autotransfusion case fatality rate of $1.9 \%$. Conclusion: In the context of shortage of blood products, autologous transfusion could be an alternative in the treatment of ruptured ectopic pregnancy in developing countries.
\end{abstract}




\section{Keywords}

Ectopic Pregnancy, Haemoperitoneum, Autotransfusion, Ouagadougou

\section{Introduction}

In developing countries, the prevalence of anemia is very high. Among the etiologies of that, many authors cite nutritional causes, infectious causes, traumatic causes, gynecology obstetric causes including haemorrhage and ectopic pregnancy (EP) broken [1] [2]. In the same context, we are witnessing to a shortage of blood products posing the problem of the treatment of this disease [3].

In these circumstances, the technique of autotransfusion, which is to retrieve, for immediate transfusion, the blood poured into the abdominal cavity, appears as an alternative to traditional transfusion [4]. The department of gynecology and obstetrics at the Schiphra Hospital in Ouagadougou, imported technique of some hospitals in the sub region including Christian Hospital Tanguiéta in Benin.

The aim of our work is to describe the experience of the obstetrics and gynecology department of the Schiphra Hospital of Ouagadougou in Burkina Faso in the management of broken ectopic pregnancy by the use of this technique very advantageous.

\section{Methodology}

It has been a cross-sectional descriptive study over a period of 18 months from January $1^{\text {st }} 2014$ to June $30^{\text {th }} 2015$ in the department of obstetrics and gynecology at Ouagadougou Schiphra hospital. The team responsible for conducting the survey had first received practical training in Christian Hospital Tanguiéta in Benin. The training lasted one month included the identification of eligible blood autotransfusion, the technique of blood collection, handling equipment for autotransfusion and monitoring of the patient transfused. The population of study was constituted by the cases of broken ectopic pregnancy with autologous transfusion.

Inclusion criteria included:

$\checkmark$ the theoretical lower gestational age was lower to 14 weeks of gestation

$\checkmark$ the chart of clinical haemoperitoneum, of abundance

$\checkmark$ the quality of the collected haemoperitoneum blood that is to say, well oxygenated, without clots and macroscopically normal

$\checkmark$ informed consent of the patient

The exclusion criteria included:

$\checkmark$ cases of homologous transfusion

$\checkmark$ patients who refused to participate in the study

$\checkmark$ macroscopic blood Appearance not acceptable and not much interesting The variables studied included age, occupation, marital status, geographical 
origin, gynecological history, clinical and para clinical at the admission and the departure of the patient. Data were collected from two structured questionnaires and were entered and analyzed using EPI-Info and MS-Excel.

We considered paucipara, patients with few previous deliveries birth to 3 times, multiparas those having between 4 and 6 births and high parity those with the number of delivery greater than or equal to 7 .

The assessment of the overall condition was performed at the admission taking into account the hemodynamic status. The general condition was considered good when:

- blood pressure was greater than or equal to $120 / 80 \mathrm{mmHg}$

- pulse including 70 to 80 beats/minute

- hemoglobin level at admission higher than $10 \mathrm{~g} / \mathrm{dl}$

The general condition was considered bad when:

- blood pressure was less than or equal to $80 / 60 \mathrm{mmHg}$

- pulse rate greater than 100 beats/minute

- hemoglobin rate at admission lower to $6 \mathrm{~g} / \mathrm{dl}$

Patients with intermediate hemodynamic status to these two clinical situations were considered to have a fair condition.

\section{Results}

\subsection{Frequency}

From $1^{\text {st }}$ January 2014 to 30 June 2015, we recorded 322 cases of ectopic pregnancy including 216 cases of unbroken ectopic pregnancy and 106 cases of ectopic pregnancy broken including 59 cases that met our inclusion criteria. The broken ectopic pregnancy accounted for $32.9 \%$ of all the EP and auto transfusion rate was $55.7 \%$.

\subsection{Socio-Demographic Characteristics}

\subsubsection{Ages}

The average age was 27 years with extremes of 18 and 40 years. Figure 1 indicates the distribution of patients according to their age group. Thirty-four patients $(57.6 \%)$ were under 30 years.

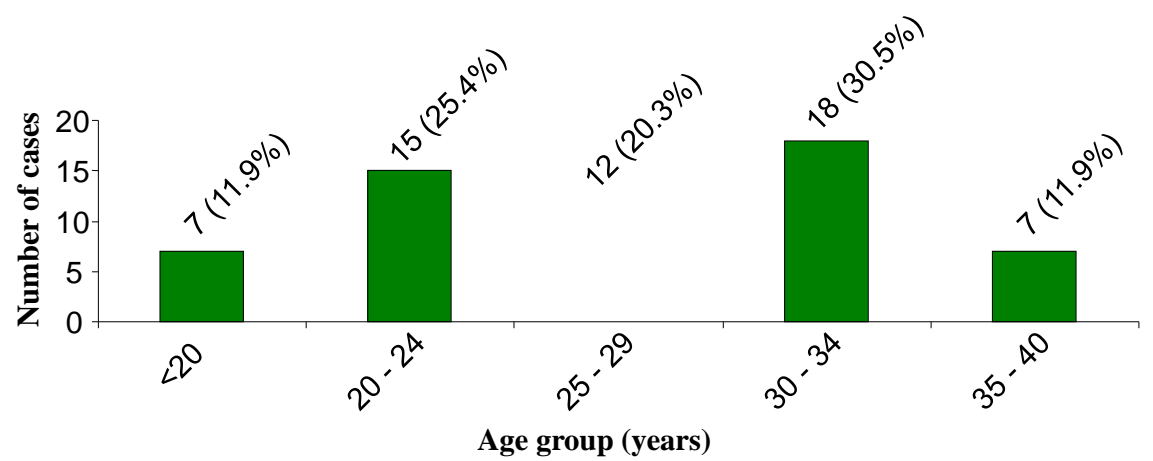

Figure 1. Distribution of patients according to the age group $(n=59)$. 


\subsubsection{Occupation}

Figure 2 gives the distribution of patients according to their profession. Housewives are the foreground with $39 \%$. The other group consisted of pupils and students.

\subsubsection{Marital Status}

Figure 3 shows the distribution of patients by marital status. Married women were the majority with $34 \%$.

\subsubsection{Number of Childbirth}

The childbirth ranged from zero to eleven with an average childbirth of 5.25. Table 1 shows the distribution of our patients according to their past childbirth. Forty one (69.3\%) patients had number of childbirth more than 4.

\subsubsection{Provenance}

In total, 47 (80\%) patients were from Ouagadougou and 12 patients (20\%) were referred from neighboring provinces.

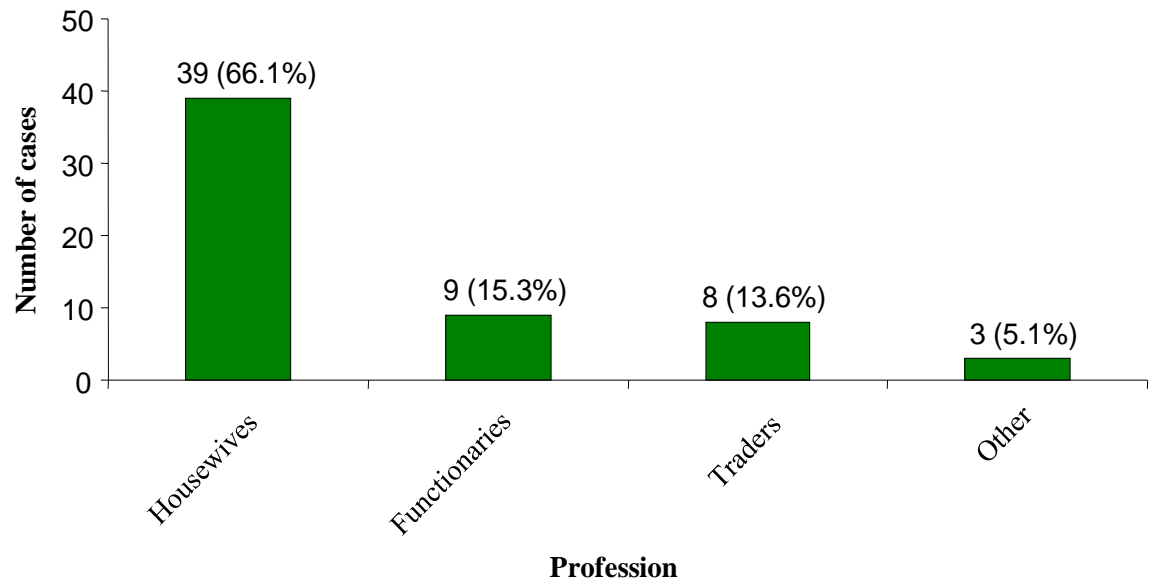

Figure 2. Distribution of patients according to the professional activity $(n=59)$.

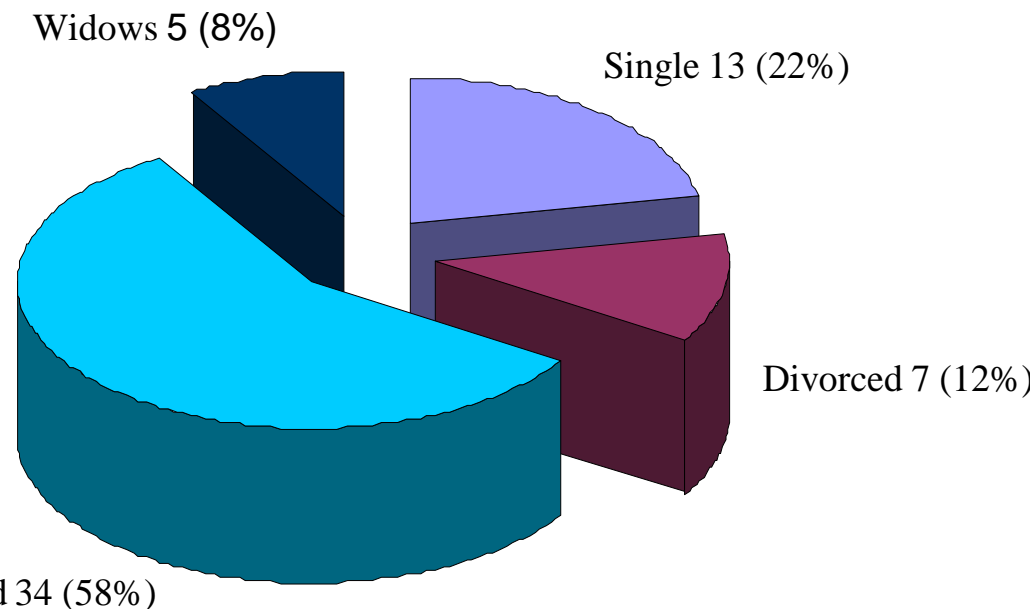

Maried 34 (58\%)

Figure 3. Distribution of patients according to the marital status $(n=59)$. 
Table 1. Distribution of the patients according to the number of past childbirth $(n=59)$.

\begin{tabular}{ccc}
\hline Number of past childbirth & Number of patients & Percentage \\
\hline 0 & 4 & $6.8 \%$ \\
1 & 8 & $13.6 \%$ \\
$5-4$ & 6 & $10.2 \%$ \\
7 and more & 18 & $30.6 \%$ \\
Total & 23 & $38.8 \%$ \\
\hline
\end{tabular}

\subsection{Clinical and Laboratory Aspects}

\subsubsection{Admission Pattern}

Table 2 shows the distribution of patients according to the pattern of admission. The triad of pelvic pain, amenorrhea, and metrorrhagia (bleeding) was absent in 49 cases $(81.9 \%)$.

\subsubsection{General State on Arrival}

The results of the assessment are shown in Figure 4. Only $8.5 \%$ of patients had a good condition at the entrance.

\subsubsection{Seat of the EP}

Figure 5 shows the distribution of patients according to the seat of EP broken. In eighteen cases (31.4\%) the seat of the EP was another but not isthmique.

\subsection{Evolution of Hemoglobin}

Figure 6 shows the distribution of patients per hemoglobin.

\subsection{Quantity of Self-Blood Transfused}

Table 3 shows the amount of self-blood transfused.

\subsection{Improved Hemoglobin}

Figure 7 shows the improvement rate of hemoglobin. Thirty six (62.0\%) patients had an improvement in hemoglobin of greater than $74 \%$.

\subsection{Hospital Stay}

Figure 8 shows the distribution of patients according to length of stay. The duration of hospitalization was less than 10 days in $95 \%$ of patients. Table 4 shows the distribution of patients according to length of stay per site.

\subsection{Complications}

Maternal prognosis was marked by a case of fever or a morbidity rate of $1.9 \%$ and a post autotransfusion death case with a fatality rate of $1.9 \%$, cases of death due to a hemorrhagic shock. We have not observed cases of jaundice or hemoglobinuria. 


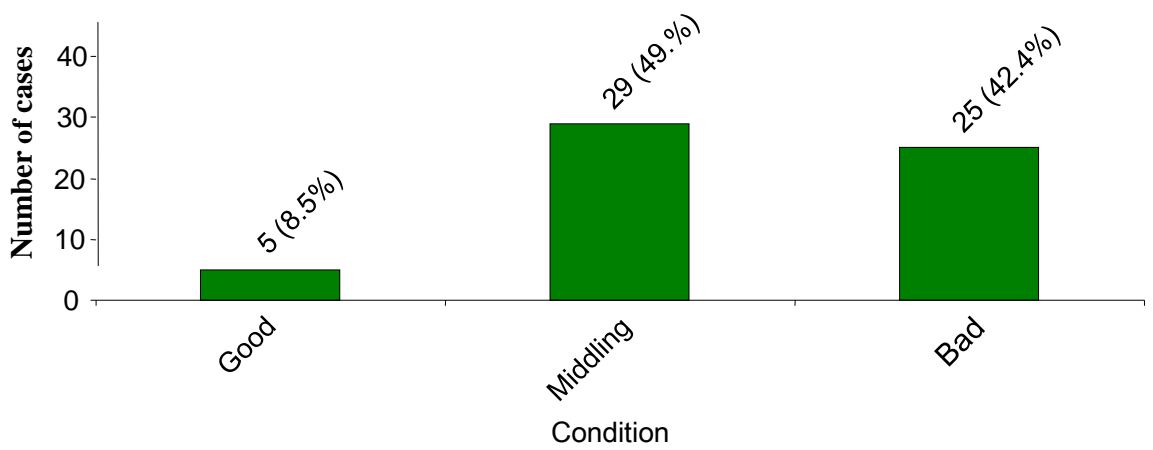

Figure 4. Distribution of patients according to their condition at admission $(n=59)$.

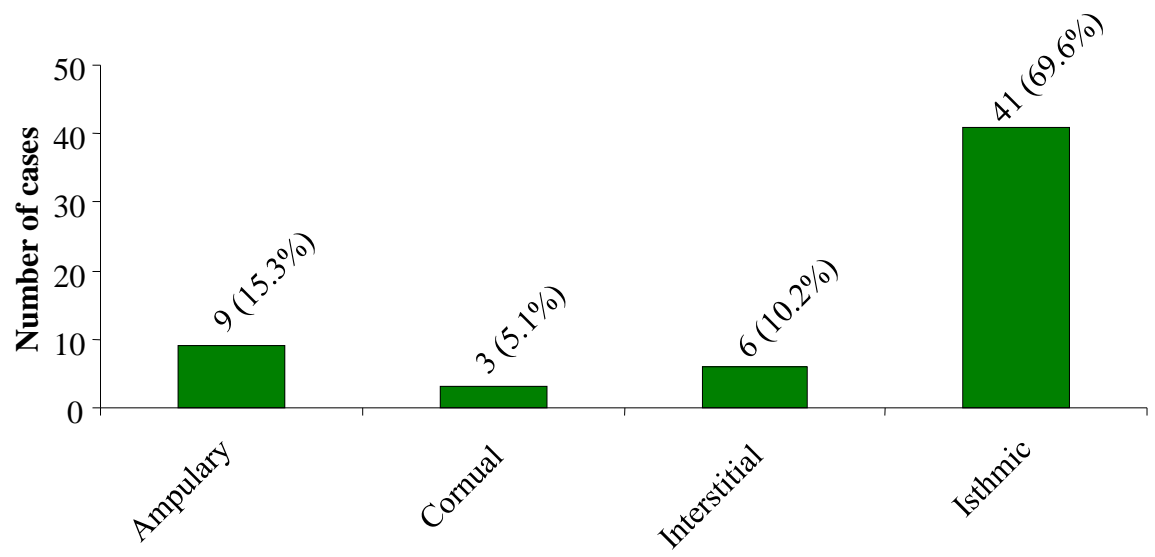

Seat of EP broken

Figure 5. Distribution of patients according to the seat of broken ectopic pregnancy $(\mathrm{n}=$ 59).

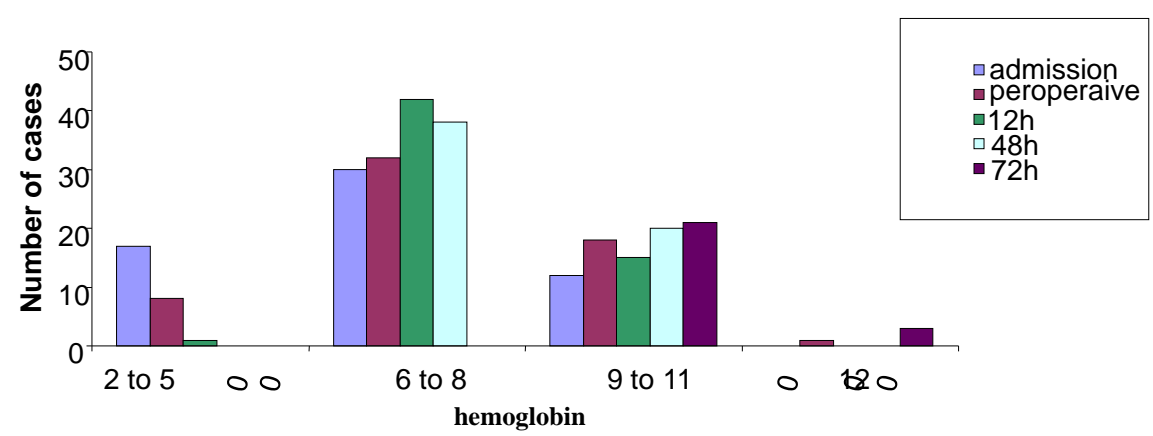

Figure 6. Distribution of patients according to the hemoglobin slices $(n=59)$.

Table 2. Distribution of patients according to the reason for admission $(n=59)$.

\begin{tabular}{ccc}
\hline Reason for admission & Number & Percentage \\
\hline Pelvic Pain-amenorrhea & 35 & $58.4 \%$ \\
Pelvic pain-amenorrhea-metrorrhagia & 10 & $16.9 \%$ \\
Pelvic pain-metrorrhagia & 14 & $23.5 \%$ \\
Total & 59 & $100 \%$ \\
\hline
\end{tabular}




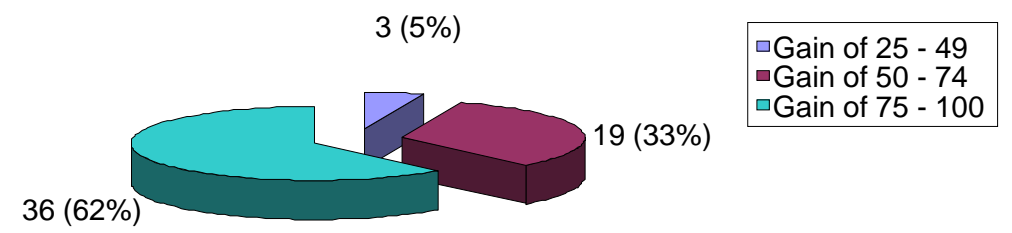

Figure 7. Distribution of patients according t the hemoglobin improvement rates $(\mathrm{n}=$ 59).

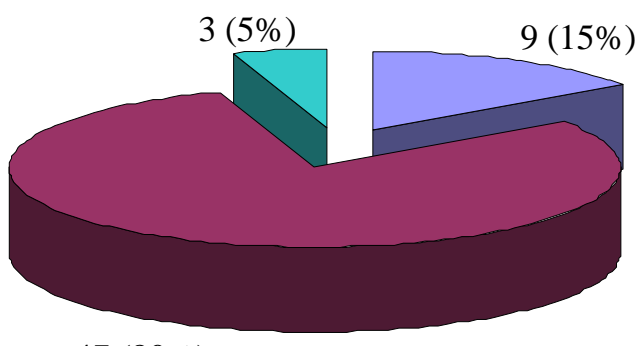

$$
\begin{aligned}
& \square 1 \text { to } 5 \text { days } \\
& \square 6 \text { to } 10 \text { days } \\
& \square>10 \text { days }
\end{aligned}
$$

$47(80 \%)$

Figure 8. Distribution of auto transfused patients according to hospital stay $(n=59)$.

Table 3. Quantity of transfused blood $(n=59)$.

\begin{tabular}{ccc}
\hline Quantity of transfused blood $(\mathrm{ml})$ & Number of patients & Percentage (\%) \\
\hline $0-500$ & 12 & 20.3 \\
$600-1000$ & 28 & 47.4 \\
$1100-1500$ & 16 & 27.0 \\
$1600-2000$ & 03 & 5.0 \\
Total & 59 & 100 \\
\hline
\end{tabular}

Table 4. Distribution of patients according to the hospitalization stay.

\begin{tabular}{ccc}
\hline Stay (days) & Number & Percentage (\%) \\
\hline $1-5$ & 9 & 15 \\
$6-10$ & 47 & 80 \\
$>10$ & 3 & 5 \\
\hline
\end{tabular}

\section{Discussion}

\subsection{Epidemiological Aspects}

\section{- Frequency}

In our series, the frequency of autologous transfusion was $55.7 \%$. Our results are lower than those of Obiechina [1] in Nigeria who reported anautotransfusion rate of $96.8 \%$. They are higher than those of Jongen VH [5] in Tanzania, who found a frequency of $43.3 \%$ in five years of practice. The low rate in our study could be explained in part by our flexible inclusion criteria and secondly by the fact that the practice was still at an early stage in the context of Burkina Faso. The great period in the study in Tanzania could actually hide confounders. Stratified analysis by shorter periods may reveal a contrary result [6]. 


\section{- Age of patients}

The average age in our study was 27 years, ranging from 18 to 40 years. Obiechina [1] found also the same range with the same average age. Kottinin [7] found an average age of 30 years. In the study by Silva [2], the average age was 31 years. In our study patients under 30 years were the most numerous. This is consistent with our cultural reality marked by early marriage especially in rural areas.

\subsection{The Seat of the Ruptured Ectopic Pregnancy}

The autotransfusion was more observed in the EP to isthmus location in our study with a frequency of $69.5 \%$. The location of the EP in our context seems concordant with the literature data. In the series of Takeda [8] in Japan it was more common in the isthmus seat. This is understandable since the isthmus portion being the thinnest, this location leads more frequently to the rupture [3] [9].

\subsection{Therapeutic Care}

\section{- Self blood transfused Quantity}

In our study, the average amount of blood received by autotransfusion was 935 milliliters of blood. Selo-Ojeme [10] reported an average amount re-transfused 1000 milliliters of blood. Yamda and Kasamatsu [11] reported an amount of between 1900 and 2600 milliliters. The amount of self-blood transfused described approximately plenty of hemoperitoneum and thereby precocity or not supported. Only 3 patients in our study had received a similar amount with the difference that in the study of Takeda [8], the auto transfused blood passed through a reduction filter system leukocyte after washing.

Given the importance of the amount of blood auto transfused, autotransfusion is a gain for our patients given the scarcity of blood products for blood transfusion in our country. Failing a whole blood bag (about 500 milliliters) is often administered to those who are lucky to have. For women Rh negative, it is even more difficult to obtain blood for homologous transfusions, which significantly increases mortality in this group.

\section{- Hemoglobin rate}

Self-transfusion helped the rise in hemoglobin of more than $60 \%$ of our patients. Twelve (12) hours after the auto transfusion, 96.5\% moved from a state of moderate to severe anemia. The same findings were made by Selo-Ojeme [10] who found a rise of hematocrit at the end of their interventions. According to him 1000 milliliters of blood auto transfused allow a rise in the average hemoglobin level from 6 to $12.5 \mathrm{~g} / \mathrm{dl}$. The rise in hemoglobin is progressive in the postoperative as evidenced Enrique study [4].

\section{Conclusion}

The broken ectopic pregnancy is frequent in Ouagadougou Schiphra Hospital; it 
quickly causes anemia and shock requiring a blood transfusion. In the developing countries facing to the difficulties for finding blood products for homologous transfusion, the autotransfusion could be an alternative in the treatment of ruptured ectopic pregnancy. Autotransfusion is easy to perform and requires little equipment. Various studies found fewer complications in it compared to homologous transfusions. It would be desirable that this technique is popularized in all our health facilities to reduce the death rate from these diseases and the risk of spread of infectious diseases such as AIDS and hepatitis. However it would be desirable that any EP is received before the break not to have to resort to autotransfusion.

\section{References}

[1] Obiechina, N., Emelife, E.C. and Ezeasor, E. (2001) The Place of Autotransfusion in Management of Ectopic Pregnancy for 9 Years Experience. Nigeria Journal of $G y$ necology and Obstetrics, 21, 513-515.

[2] Silva, P.D. and Beguin Jr., E.A. (2009) Intraoperative Rapid Autologous Blood Transfusion. American Journal of Obstetrics \& Gynecology, 160, 1226-1227.

[3] Binam, F., Takongmo, S., Waffo, J.L., Zekeng, L. and Kaptuel (2007) Homologous Blood Saving Surgery Delayed Auotransfusion. A Comparative Study of $205 \mathrm{~Pa}$ tients. Black African Medicine, 44, 47-53.

[4] Enrique, A., Bonfils-Roberts, C., Leonard, S., Thomas, F. and Nealon, J.R. (2004) Autologous Blood in the Treatment of Intraoperative Hemorrhage. St. Vincent Hospital and Medical Center of New York, and New York University Medical School, 153 West 11th Street, New York, 32 p.

[5] Jongen, V.H. (2007) Autotransfusion and Ectopic Pregnancy: An Experience from Tanzania Ndala Hospital. Tanzanian Too Medical Doctor Journal, 27, 78-79.

[6] Bonnet, A., Bourdallé-Badie, C., Clmatte, C., Darmendrall, V., January, G., Torrielli, R., Erny, P. and Chevais, R. (2005) Autotransfusion in Vascular Surgery. Hematological Study. American French Journal of Anesthesia, 16, 485-572.

[7] Kottin, A. (2015) Contribution to the Study of USG in Cotonou. Thesis No. 060, Benin, West Africa.

[8] Takeda, A., Manabe, S., Mitsui, T. and Nakamura, H. (2006) Management of Patients with Ectopic Pregnancy with Massive Hemoperitoneum by Laparoscopic Surgery with Intraoperative Autologous Blood Transfusion. Journal of Minimally Invasive Gynecology, 13, 43-48.

[9] Bird, G.W.G. (2011) The History of Blood Transfusion Injury. Imperial College Press, New York, 56.

[10] Selo-Ojeme, D.O., Onwudiegwu, U., Durosinmi, M. and Owolabi, A.T. (1997) Emergency Autologous Blood Transfusion in the Management of Ruptured Ectopic Pregnancy. Journal of Obstetrics and Gynaecology, 17, 353-355.

[11] Yamada, T. and Kasamatsu, H. (2003) Laparascopic Surgery with Intraoperative Autologous Transfusion in Patients with Bloob Heavy Hemoperitoneum Due to Ectopic Pregnancy. JSLS, 7, 97-100. 